\title{
Sexualidade e educação: o Centro de Aconselhamento e Orientação de Jovens (CAOJ) de Coimbra-PT enquanto espaço de formação
}

\author{
Sexuality and education: the Counseling Center and Youth \\ Guidance (CAOJ) of Coimbra, Portugal, as a training space
}

\author{
Heloisa Raimunda Herneck ${ }^{1}$. Carlos Eduardo Ferraço ${ }^{2}$. \\ Maria Filomena Rodrigues Teixeira ${ }^{3}$
}

\begin{abstract}
Resumo: Esse artigo objetiva relatar o desenvolvimento de uma formação de voluntários para intervenção no Projeto Nacional de Educação pelos pares da Fundação Portuguesa 'A Comunidade Contra a SIDA' - trata-se de uma pesquisa de pós-doutorado realizada em Coimbra, Portugal. A abordagem metodológica adotada foi a da pesquisa nos/dos/com os cotidianos, discutindo a formação continuada de docentes, a partir dos cotidianos escolares e dos regimes de verdade partilhados sobre sexualidades, especialmente em relação à população LGBTTI. Considera-se a experiência portuguesa relevante para refletir sobre as ausências de discursos que promovam o debate de outras vidas possíveis no ambiente escolar a partir de formação docente em Portugal e no Brasil.
\end{abstract}

Palavras-chave: Sexualidade. Educação sexual. Formação continuada de professores. Portugal. AIDS.

\begin{abstract}
This paper aims to report the experience of training volunteers to intervene in the National Project of Education by the Partners of the Portuguese Foundation 'Community Against AIDS'. The methodological approach used was everyday life research, looking at teachers' ongoing training, everyday school experience and the truth regimen shared about sexualities, mainly by the LGBTTI community. The Portuguese experience is considered relevant in order to reflect on the absence of discourses that promote the debate on other possible lives within the school, based on the teachers' training both in Portugal and in Brazil.
\end{abstract}

Keywords: Sexuality. Teachers training course. Portugal. CIDA.

\footnotetext{
${ }^{1}$ Universidade Federal de Viçosa (UFV), Viçosa, MG, Brasil. E-mail:<hherneck@gmail.com>

${ }^{2}$ Universidade Federal do Espírito Santo (UFES), Departamento de Educação, Vitória, ES, Brasil.

${ }^{3}$ Instituto Politécnico de Coimbra, Escola Superior de Educação, Coimbra, Portugal.
} 


\section{Introdução}

O processo de formação está pensado, melhor dizendo, como uma aventura. E uma aventura é, justamente, uma viagem no não planejado e não traçado antecipadamente, uma viagem aberta em que pode acontecer qualquer coisa, e na qual não se sabe onde se vai chegar, nem mesmo se vai chegar a algum lugar (LARROSA, 2006, p. 52-53).

Assim como o não planejado de Jorge Larrosa (LARROSA, 2001), nos aproximamos do tema sexualidade no momento de pós-doutoramento realizado no Instituto Politécnico de Coimbra, Escola Superior de Educação de Coimbra (ESEC) nos meses de setembro a dezembro de 2014. Nossa chegada foi marcada pelo curso de "Formação para voluntários/as de intervenção no Projeto Nacional de Educação pelos pares da Fundação Portuguesa 'A Comunidade Contra a SIDA ${ }^{4}$ (FPCCSIDA)". Dentre as temáticas abordadas estava a sexualidade em uma perspectiva aberta à diversidade em práticas educacionais.

O presente texto compõe-se de reflexões com/ a partir de/sobre $e^{5}$ o curso, enquanto um acontecimento, no sentido definido por Larrosa (2014, p. 22) como “[...] aquilo que nos é dado na forma de choque, do estímulo, da sensação pura, na forma de vivência instantânea, pontual, fragmentada". Esse conceito nos parece apropriado para pensar a contemporaneidade, marcada pela velocidade dos acontecimentos e pela necessidade de novidades, o que, às vezes impede conexões significativas. Assim, as conexões aqui realizadas têm como base os sentidos por nós atribuídos a esses acontecimentos e ao "[...] modo como nos colocamos diante de nós [mesmas], diante dos outros e do mundo em que vivemos. E o modo como agimos em relação a tudo isso" (LARROSA, 2014, p. 17).

O curso faz parte do Projeto Nacional de Educação pelos Pares (PNEP), sendo continuidade do programa "Educação em sexualidade e Prevensão da infecção HIV/SIDA", desenvolvido em parceria com o Ministério da Educação e Ciência de Portugal. Sua atuação abrange algumas escolas básicas e secundárias de Coimbra, Porto, Lisboa e Setúbal. Dentre os objetivos do programa está a formação de docentes centrada nos projetos de educação sexual das escolas/agrupamentos; a formação de assistentes operacionais de educação; a sensibilização de pais e encarregados/as de educação e a valorização e qualificação do voluntariado jovem universitário. O Centro de Aconselhamento e Orientação de Jovens (CAOJ) coordena o curso atuando na formação de jovens interessados/as em voluntariado nas escolas do terceiro ciclo para atuar com dinâmicas envolvendo corpo, sexualidade e violência doméstica.

Trata-se, portanto, de um processo de formação continuada que se enreda com/em cotidianos dos contextos educacionais, evocando questões específicas, mas que não se reduzem

\footnotetext{
${ }^{4}$ Trata-se da sigla utilizada no português de Portugal para referir-se à AIDS.

${ }^{5} \mathrm{O}$ ato de juntar palavras para formar outros sentidos não binários tem como base as inventividades nos estudos $\mathrm{com} / \mathrm{nos} /$ dos cotidianos desenvolvidos por Nilda Alves (ALVES, 2008) e seu grupo. Trata-se de uma opção política, ética e estética que preza pela ressignificação de termos convencionados como opostos ou descolados, para pensa-los de forma relacional.
} 
ao local, pois assumem o vivido pelos sujeitos em diversos espaçostempos. As atividades desenvolvidas com a participação dos/as professores/as das escolas durante seus horários de aula são dirigidas aos/as alunos/as. Os/as jovens voluntários/as, que também estão em processo de formação, refletem sobre a temática da sexualidade durante o curso e constroem conceitos que rompem com as modalidades dominantes até então conhecidas sobre a sexualidade. São convidados/as a outras maneiras de ver, escutar, sentir, à medida que são inqueridos/as por questões inesperadas que surgem no decorrer do curso (FERRAÇO, 2008).

As vivências $\mathrm{com} /$ no curso de formação continuada de professores/as dispararam reflexões sobre a sexualidade. Em nossas vivências anteriores de pesquisas com escolas de Educação Básica, relacionamentos entre sujeitos LGBTTIs ${ }^{6}$ não eram representados ou sequer mencionados e as temáticas ligadas a gênero e sexualidade haviam sido pouco exploradas ou até mesmo silenciadas nos espaços formativos dos professores/as.

Nossos estudos anteriores (FERRAÇO, 2007, 2008; HERNECK, 2002, 2008) mostram que as propostas de formação continuada para docentes no Brasil, geralmente privilegiam conteúdos relacionados ao ensino de Língua Portuguesa e Matemática, com especial enfoque à aprendizagem dos conteúdos de ensino e os aspectos didáticos e metodológicos. Quando há espaços para outros conteúdos, no caso em Ensino de Ciências ou Biologia, a sexualidade aparece na maioria das vezes como tema transversal ou ligado a cuidados com a saúde. Nesses espaços discursivos estudantes e professores/as são considerados sujeitos de uma sexualidade dada e biologizada, calcada na universalidade.

\section{Acontecimentos e pesquisa: agenciamentos cotidianos}

Esses momentos, movimentos, processos, tentativas, possibilidades, de pensar "com" os cotidianos, de me pensar, possibilitam que eu me conheça ao mesmo tempo em que busco conhecer os outros... (FERRAÇO, 2008, p. 161).

Não houve uma definição a priori do tema dessa pesquisa. A sexualidade emergiu a partir do interesse pelas temáticas ligadas às representações visuais, e aos processos de subjetivação nas/das/com as redes vivenciadas nos cotidianos dentrofora das escolas e dos processos cotidianos com os quais nos envolvemos no curso. Ao chegar a Coimbra-Portugal nos deparamos com um evento de formação que faz parte do Projeto Nacional de Educação pelos Pares da FPCCSIDA. Nessa formação, apesar do foco ser prevenção e combate a AIDS, fomos atraídos/ as pelos trabalhos envolvendo sexualidade que eram realizados com os/as jovens participantes

\footnotetext{
${ }^{6}$ Nesse texto a sigla LGBTTIs se refere a Lésbicas, Gays, Bissexuais, Travestis, Transexuais (mulheres, homens trans e pessoas não binárias) e Intersex. Há a compreensão de que essa sigla, assim como qualquer outra, é sempre reducionista, pois há pessoas cujas identidades de gênero e orientação sexual não são consideradas pelos termos que as compõem, mas a usamos como indicativo de um grupo autonomeado que se organiza sob essas classificações para demandar direitos sociais.
} 
e a forma como eles/as respondiam às temáticas propostas. Entendendo que no processo de formação devemos estar propensos/as a conhecer e valorizar as experiências ${ }^{7}$, ampliamos a discussão, já cientes que "[...] o que se vê nunca é o que havíamos pensado, ou sonhado, nunca é a ordem do 'previsto'[...]" (LARROSA, 2014, p. 75). Assim, decidimos possibilitar essa formação, sentindo seus tremores, fazendo conexões, mas sempre com uma abertura para a pergunta, para o que não sabíamos.

Essa pesquisa adota uma abordagem pós-estruturalista com uma metodologia que se inscreve nos modos de fazer pesquisa com/nos/dos cotidianos. Isso significa que nossa aproximação do lócus e sujeitos de pesquisa não tem um caminho pré-definido e imutável, mas adapta-se ao que é posto pelas experiências do próprio pesquisar. Em outras palavras, não partimos de um

[...] sistema formal de categorias a priori, conceitos, estruturas, classificações, ou outras formas de regulação, de ordenação exterior à vida cotidiana; mas consideramos a possibilidade de pensar o cotidiano como redes de saberesfazeres tecidas pelos sujeitos cotidianos [...] (FERRAÇO, 2007, p. 162).

Nesse sentido,

As ênfases - quais eventos interessam e o quanto eles interessam - dependem do que pode ser visto e pensado no horizonte de cada sistema de pensamento. Além disso, qualquer evento só é mesmo evento para nós se faz algum sentido para nós; ele só é evento se tem algum acolhimento, por menor que seja, pelo sistema de pensamento em que nos situamos e o qual partilhamos com os outros (VEIGA-NETO, 2005, p. 11).

As pesquisas com os cotidianos estão sempre abertas ao imprevisto, ao fluxo, aos acontecimentos, e são as redes que tecemos enquanto as praticamos que compõem nossos saberesfazeres. Por isso, como Ferraço (2008), valorizamos a pluralidade de possibilidades que se abrem para pesquisadores/as da educação e professores/as em formação quando em contato com " [...] um processo de formação continuada que aconteça em meio às redes cotidianas, evocando questões específicas, mas que não se reduzem ao local, e assuma o cotidiano vivido enquanto espaçotempo de análise da complexidade da educação [...]” (FERRAÇO, 2008, p. 21).

Considerando a complexidade da educação, não podemos pensar a formação de professores/as restrita às redes desenvolvidas "dentro" do espaço escolar, já que não há paredes que limitem os acontecimentos e experiências.

Buscamos então assumir que os corpos não ocupam apenas um lugar, conforme Certeau (2011, p. 184):

\footnotetext{
${ }^{7}$ Ao longo do texto usamos o termo "experiência" com a significação do conceito de Larrosa (2014), nos referindo ao acontecimento que atua como disparador de processos de subjetivação.
} 
Um lugar é a ordem (seja qual for) segundo a qual se distribuem elementos nas relações de coexistência. Aí se acha, portanto, excluída a possibilidade, para duas coisas, de ocuparem o mesmo lugar. Aí impera a lei do "próprio": os elementos considerados se acham uns ao lado dos outros, cada um situado num lugar "próprio" e distinto que define. Um lugar é, portanto, uma configuração instantânea de posições. Implica uma indicação de estabilidade.

Nesta perspectiva, estamos nos comprometendo com os espaços, pensados enquanto lugares praticados, especificados “[...] pelas ações de sujeitos históricos [...]” (CERTEAU, 2011, p. 185, grifo nosso), que os configuram a partir delas.

Essas ações enunciam as diversas redes em que nos compomos enquanto sujeitos dos acontecimentos sofridos, padecentes, receptivos, aceitantes, interpelados, submetidos. Somos o tempo todo atravessados por diferentes e variadas redes, fazemos conexões, produzimos e somos produzidos.

Em qualquer caso, seja como território de passagem, seja como lugar de chegada ou como espaço do acontecer, o sujeito da experiência se define não por sua atividade, mas por sua passividade, por sua receptividade, por sua disponibilidade, por sua abertura. Trata-se, porém, de uma passividade feita de paixão, de padecimento, de paciência, de atenção, como uma receptividade primeira, como uma disponibilidade fundamental, como uma abertura essencial (LARROSA, 2014, p. 26).

Essa definição do sujeito a partir de sua abertura à experiência pode ser pensada por meio das atualizações constantes que os acontecimentos nos impõem. Dessa forma, o acontecimento faz parte de uma lógica do devir-vida, pensando com Larrauri (2009, p. 54) que "[...] o devir é algo que acontece a duas coisas que se encontram, e isso que acontece não pertence à ordem do reconhecimento ou do julgamento, mas à da captura ou do roubo". Nesta lógica, o que acontece nos captura, nos toma de assalto e ressignifica, num processo contínuo constituído pelas experiências às quais nos permitimos, nos abrimos, recebemos.

E assim, foi no campo dos devires que nos propusemos a problematizar - acontecimentos compartilhados durante a formação para os/as voluntários/as. Selecionamos aqueles/ as que mais nos sensibilizaram. E foi nas ausências, nos não ditos, que fomos provocados a pensar, como cantos de protestos ou de luta contra as formas dominantes de linguagem, de pensamento e de subjetividade (LARROSA, 2014).

Essa menção traz à tona a questão do acontecimento, como algo que “[...] nos é dado na forma de estímulo, sensação pura, na forma da vivência instantânea, pontual, fragmentada [...]" (LARROSA, 2014, p. 22), de forma que entendemos nesta escrita que o estímulo também pode ser uma ausência, um silêncio, um apagamento.

Os acontecimentos compõem os processos de subjetivação. Estabelecemos assim que não é possível falar de subjetividade em geral nem de Sujeito Universal, mas somente de subjetividades práticas e sujeitos que se constituem na experiência social, em seus trajetos singulares, na sua família, na escola, na rua, no seu corpo, no escritório, etc. Portanto, subjetividade é tudo aquilo que concorre para a produção de um 'si', um modo de existir, um estilo de existência que não é dado ou fixo, mas processual e disparado por experiências e acontecimentos. 
A subjetividade se dá na relação com o mundo, com a linguagem, com o pensamento, com o que somos e o que fazemos com o que já estamos deixando de ser. Assim, cada evento de formação, pode ser entendido como um acontecimento que produz sujeitos e é por eles produzido. A essa produção denominamos de processos de subjetivação e (des) subjetivação que os/as compõem.

Ao nos referirmos às modificações ocasionadas na medida em que praticamos os cotidianos, não podemos nos esquecer de que também estamos nos referindo à “[...] subjetividade distribuída, socialmente construída, dialógica, descentrada, múltipla, nômade, situada, de subjetividade inscrita na superfície do corpo, produzida pela linguagem [...]" (DOMÈNECH; TIRADO; GÓMEZ, 2001, p. 113), que se dá em processo enquanto produzimos, somos produzidos/as pelos cotidianos vividos.

Para Carvalho (2011, p. 60), estes momentos da formação “[...] se expressam, pelas conversações, em redes de subjetividades compartilhadas, envolvendo fluxos e forças de agenciamentos de um corpo político de outra ordem ou natureza e, pela potencialidade das redes de conversações na formação [...]" em sua dimensão cognitiva, afetiva e política. Numa rede de conversações como esta, “[...] insere-se tanto a luta pelo discurso, o silêncio repressivo, como passagem do diálogo para a multiplicidade e a heterologicidade".

Nosso envolvimento no curso nos impeliu ao uso da fotografia, do ouvir, do registrar e do compor a partir dos e com os acontecimentos ali experimentados. Produzimos imagens, pois acreditamos que as realidades são produções discursivas que criamos em nossas redes de significações, enquanto regime de verdade (FOUCAULT, 2003). Embora geralmente tentemos representar essa produção em palavras, as imagens nos servem como disparadoras, desafiadoras, desdobradoras de muitos sentidos a mais do que a escrita nos permite. As imagens escolhidas foram as que nos ajudaram a pensar os acontecimentos, experiências, que aqui significamos em algumas de suas infinitas possibilidades. Daí a importância das fotografias, elas trazem consigo algo do devir-pesquisa, menos fechado, mais rizomático e cheio de possibilidades (DELEUZE, 2010).

É possível [...] desviar de sua compreensão como documentos, como provas, como artifícios de trazer sujeitos reais, situações concretas e aspectos de contexto para a escrita que quer se impregnar cotidiano. [...] é importante que se tomem as fotografias não apenas como interface entre o visual cotidiano e as linguagens que apresentam o mundo de maneira mais codificada [...]. Por entre escritos e imagens, esse texto desloca potencialidades dessas hifenizações e põe atenção para o acontecimento (AMORIM, 2008, p. 115-116, grifo do autor).

Assim, apresentamos as imagens produzidas por nós junto ao CAOJ no projeto Nacional de Educação pelos pares da FPCCSIDA, de Coimbra (Portugal), durante os meses de setembro a novembro de 2014. Importante ressaltar que a própria seleção da imagem já é uma composição, uma produção discursiva em si. Esta seleção se dá a partir de nossos afetos, nossos amores e desamores, nossos sentidos e nossas relações subjetivas como agenciadores dos sentidos de verdade e problematizações que se enredam em nossos discursos. 


\section{A Comunidade Contra a AIDS: um espaço de formação}

As diferentes experiências são traçadas evidenciando o desenho deste encontro que não é igual ao anterior e nem será igual ao próximo, pois cada ensaio tece um afeto modificador de si (FOUCAULT, 1994, p. 15).

O curso está regulamentado pela Portaria n. ${ }^{\circ}$ 196-A/2010, que inclui nos currículos do ensino básico e secundário de Portugal a integração da área de educação para a saúde. $\mathrm{O}$ documento traz como dimensão ética da sexualidade, a sua compreensão como um dos componentes mais sensíveis da pessoa, devendo ser "[...] desenvolvida em um projeto que integre valores como: afectos, ternura, crescimento e maturidade emocional, capacidade de lidar com frustrações, compromissos, abstinência voluntária, e uma dimensão ética” (PORTUGAL, 2010). Além desses, coloca como objetivos da educação sexual no $3 .^{\circ}$ ciclo:

Compreensão da fisiologia geral da reprodução humana; Compreensão do ciclo menstrual e ovulatório; Compreensão do uso e acessibilidade dos métodos contraceptivos e, sumariamente, dos seus mecanismos de acção e tolerância (efeitos secundários); Compreensão da epidemiologia das principais IST em Portugal e no mundo (incluindo infecção por VIH/vírus da imunodeficiência humana - HPV2/vírus do papiloma humano - e suas consequências) bem como os métodos de prevenção. Saber como se protege o seu próprio corpo, prevenindo a violência e o abuso físico e sexual e comportamentos sexuais de risco, dizendo não a pressões emocionais e sexuais; Conhecimento das taxas e tendências de maternidade e da paternidade na adolescência e compreensão do respectivo significado; Conhecimento das taxas e tendências das interrupções voluntárias de gravidez, suas sequelas e respectivo significado; Compreensão da noção de parentalidade no quadro de uma saúde sexual e reprodutiva saudável e responsável; Prevenção dos maus tratos e das aproximações abusivas (PORTUGAL, 2010, p. 1170-(4)).

Interessam-nos os processos de negociação dos sujeitos envolvidos nesta formação e o que produzem a partir dela, para além dos currículos prescritos e das previsões legais, ainda que estas sejam também disparadoras das práticas pedagógicas vividas.

O curso inicial para os/as voluntários / as foi realizado em setembro de 2014 na Faculdade de Medicina da Universidade de Coimbra. Os/as estudantes participantes são voluntários/ as das Brigadas Universitárias de Intervenção (BUI), que após participação nesta primeira etapa sobre temáticas ligadas à sexualidade, em particular a infeção HIV/AIDS, afetos e consumo de substâncias psicoativas, são subdivididos em grupos com um/a professor/a responsável do CAOJ. Estes grupos fizeram intervenções nas escolas, trabalhando com jogos pedagógicos e dinâmicos, seguidos por reflexão e debates em tempos curriculares acordados com as escolas, conforme também prevê a Portaria n. ${ }^{\circ}$ 196-A/2010 (PORTUGAL, 2010).

Por meio do projeto, os/as voluntários/as são instigados/as a trazer seus vínculos afetivos, seus sentires, e a produzir sentidos sobre sexualidades enquanto estabelecem diálogos consigo mesmos/as, com o mundo, com a linguagem, com o pensamento, com o que são e o que podem vir a ser. 
Herneck, H. R.; Ferraço, C. E.; Teixeira, M. F. R.

O curso foi composto por dois tempos/módulos: o primeiro com palestras realizadas por especialistas de saúde e de educação sobre questões relacionadas à violência doméstica, infeção HIV/AIDS, etc.; o segundo com vivências e dinâmicas abordando as temáticas já discutidas nas palestras.

Durante a formação, os/as jovens voluntários, oriundos/as de diferentes cursos de graduação (Medicina, Ciências da Educação, Biologia, Direito, Psicologia, Enfermagem), foram convidados/as a participar de dinâmicas que propiciavam a interação do grupo. A equipe do CAOJ formada pelos/as coordenadores/as e professores/as da rede pública de ensino de Coimbra, Portugal, sugeriam as atividades e iniciavam o seu desenvolvimento.

\section{Puxar o fio, formar a rede, fazer conexões!}

Figura 1. Dinâmica "Conhece-te a ti mesmo"

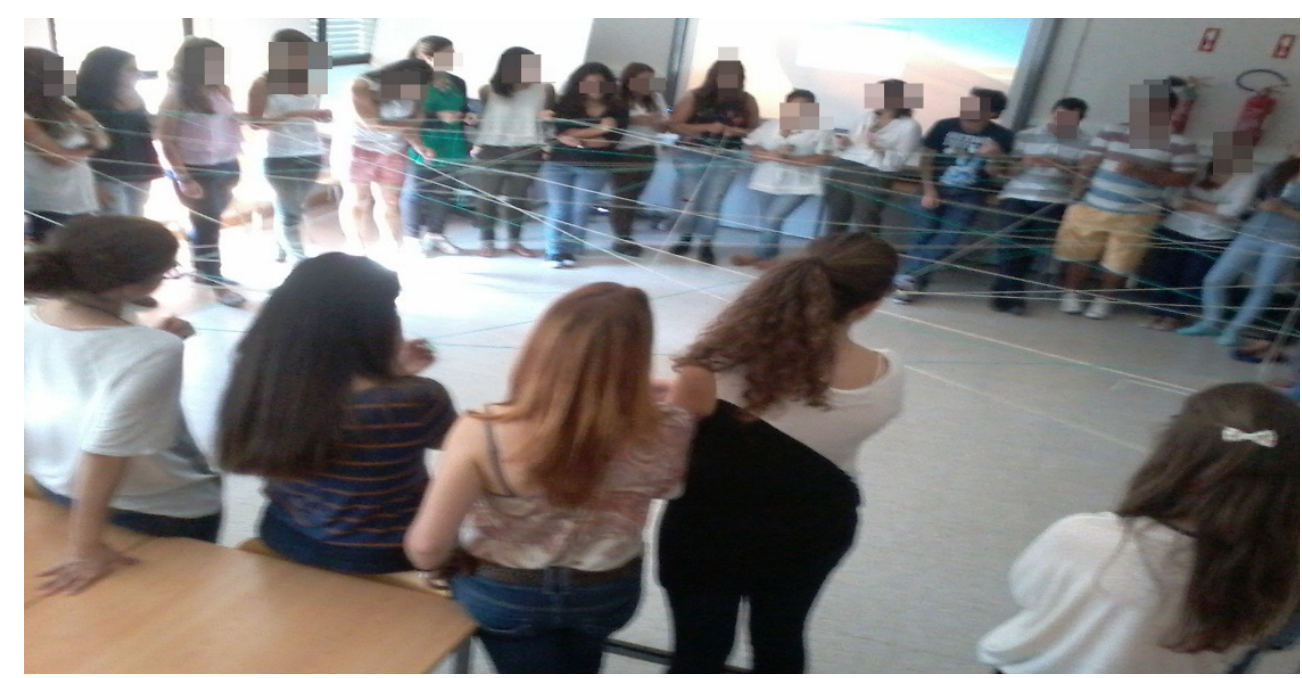

Fonte: Arquivo pessoal das autoras.

Conhece-te a ti mesma! A individualidade de cada um/a constitui-se em multiplicidades à medida que são dinamizadas as conversações. Os corpos são convidados a se mexerem, a se deslocarem de sua zona de conforto para a movimentação. O novelo é o objeto que se move, de um lado a outro. Em cada ponto, um nome, uma história, uma conexão. Sorrisos, cochichos, expressões preocupadas... Invenções! O corpo responde, e num vai e vem, a rede vai sendo formada.

A proposta foi que a partir do próprio nome, buscassem seu significado e/ou o motivo de tê-lo recebido, e socializassem ao grupo. A seguir, deveriam escolher um colega e lançar novamente o novelo. Conexões são realizadas para buscar na lembrança algo aparentemente óbvio, mas às vezes, nunca antes pensado: homenagens carinhosas, presença e ausência da 
figura paterna, traições, alcoolismo, etc... Tudo isso aparece ligado às histórias dos nomes. Mas contado de um jeito engraçado: "Eu ia me chamar Cassiana", mas meu pai bebeu uns goles e pelo caminho esqueceu o nome que minha mãe havia escolhido... achou que Cássia era o mais parecido, pronto, ficou Cássia!!! Colocou este mesmo!!!". "Minha mãe queria Tatiane, minha vó não deixou. Depois descobrimos que meu pai tinha uma filha fora do casamento que se chamava assim". "Nunca soube o porquê me chamava Brenda, e ninguém me explicava... um dia descobri que tinha uma marca de cerveja com esse nome". "Bom, meu nome é José, porque meu pai é José, meu avô é José, então, eu também sou José igual a eles”. Entre as conversações um lugar para o afeto, para o riso, para a descontração.

Segundo Carvalho (2011, p. 60), estes momentos da formação “[...] se expressam, pelas conversações, em redes de subjetividades e sociabilidades compartilhadas, envolvendo fluxos e forças de agenciamentos de um corpo político de outra ordem ou natureza e, pela potencialidade das redes de conversações na formação [...]" em sua dimensão cognitiva, afetiva e política. Numa rede de conversações como esta, "insere-se tanto a luta pelo discurso, o silêncio repressivo, como passagem do diálogo para a multiplicidade e a heterologicidade" (CARVALHO, 2011, p. 65). Desta forma, “[...] o deslocamento do diálogo ou do silêncio para a multiplicidade refere-se ao discurso ao lado do discurso, ou seja, não necessariamente contra ou a favor [...]" (CARVALHO, 2011, p. 65). Assim, “[...] a participação de cada um, dá lugar à pluralidade e a polifonia, assumindo um estado descentrado, de tal modo que é a pluralidade e não o Eu ou o Outro que será o foco do encontro [...]" (CARVALHO, 2011, p. 65), envolvendo vozes, tópicos, contextos e formando redes. Neste sentido, é necessário pensar o devir no sentido de deixar-se contagiar.

A rede de sociabilidade ali produzida depende em sua condução, da vontade de cada $\mathrm{um} / \mathrm{a}$ dos/as parceiros/as, em socializar o seu individual na coletividade. Portanto, os fluxos são vários, assim como as possibilidades de reflexão e de afetos. Dessa forma, a rede de conversação discorre, flui, de modo que cada um/a é convidado/a a entrar no fluxo do pensamento do/a outro/a, sendo contagiado/a pelo próprio movimento, de fazer com que as ideias e as mentes movam-se, como os corpos quando se agitam ao ritmo da música que os invade (LARRAURI, 2009), em que uma rede de afetos, ternura, maturidade emocional, frustrações é acionada - misturas -, conforme Larrosa (2014), trata-se de acontecimentos sofridos, padecentes receptivos, aceitantes, interpelados, submetidos.

Com essa atividade, os/as participantes são convidados a pensar a vida, pois não podemos viver sem amar, sem desejar, sem nos deixar arrastar pelo próprio movimento da vida. E, nesse sentido, amar a vida é amar a diferença, o fluxo, o perpétuo movimento. A vida é aquilo em que nos encontramos envolvidos, que nos faz pulsar, que nos faz caminhar, que nasce aquém de nós e nos leva além de nós. Uma vida gozosa que se move por desejos e por alegrias.

Nesse momento de nosso contato com os cotidianos, o acontecimento pede passagem e o momento passa demasiadamente depressa. Um estímulo é substituído por outro. Como nos ensina Larrosa (2014), a velocidade com que são dados os acontecimentos impede a conexão significativa entre eles. Impede também a memória, já que cada acontecimento é imediatamente substituído por outro que igualmente excita por um momento, mas sem deixar qualquer vestígio. Muitas histórias, risos, aproximações... A individualidade dá lugar às redes de subjetivação coletivamente produzidas.

\footnotetext{
${ }^{8}$ Todos os nomes são fictícios para preservar a identidade dos jovens. As situações são reais.
} 
Durante as movimentações, em que as experiências privadas eram partilhadas, alguns aspectos foram problematizados. Nos trabalhos em grupos, eles se agrupavam ao acaso, ou por preferências em trabalhar mais com um/a ou com outro/a. Percebíamos que parte dos/as estudantes participava ativamente daquelas atividades. As ações e manifestações pareciam estar sempre regidas pela heteronormatividade enquanto referência única. Incomodava-nos, naquele momento, o silenciamento de outras existências possíveis (DELEUZE, 2010). Relacionamentos entre sujeitos LGBT'TIs não eram representados ou sequer mencionados.

Foram convidados/as a escrever palavras ligadas à sexualidade em uma tarefa individual. Posteriormente, a formar conceitos a partir das palavras. Nosso olhar se afixa sobre a folha de papel de um estudante que escreveu palavras como "medo", "insegurança". Nos conceitos, entretanto, as mesmas não aparecem. Conceitos foram formados pelos grupos onde aparecem palavras como "prazer", "carinho", "amor", "sentimento". O que terá acontecido com o "medo" e a "insegurança" do jovem? Terá sido engolido pela travessia do perigo, pelo medo à exposição, da receptividade dos colegas? Terá o acontecimento paralisado a experiência?

Nosso olhar, que também não é desprovido de experiências, permeado por histórias de vida, fez-nos perceber que havia uma matriz heterossexual que delimitava os padrões a serem seguidos por aqueles/as jovens, mesmo que não verbalizados. A partir deste momento, fomos afetadas pelo silêncio em relação à homossexualidade e passamos a produzir sentidos sobre/ com/por esse campo. Atentamos-nos para os sentidos produzidos por aqueles/as jovens e as conexões que fariam. Em que momento comporiam também com os outros modos de ser, de se relacionar, de viver a sexualidade que não a normatividade que traziam em suas falas?

Chamava-nos a atenção essa ausência, uma vez que dialogavam sobre a AIDS, que por muito tempo esteve ligada aos LGBTTIs. São também estes temas muito apresentados pelas mídias. Somos quase o tempo todo convidados/as a pensar, a viver, a compor sobre as diferenças em relação à sexualidade no mundo contemporâneo. Percebemos, com certo estranhamento, o como não se posicionavam diante de outros modos de ser, de vivenciar a sexualidade. Pareciamnos muito formatados/as na heteronormatividade.

Convidados/as a dramatizar situações envolvendo violência doméstica, novamente a ausência de problematizações relativas às relações homoafetivas. Neste momento, essa ausência já conduzia nossos sentidos e se tornara objeto de nossas perguntas.

Quando os grupos foram convidados a dramatizar histórias por eles/elas criadas para representar um tipo de violência doméstica, também nenhum grupo abordou situações de violências relacionadas ao público LGBTTIs. Até mesmo grupos formados somente por mulheres criaram histórias em que uma fazia o papel de homem para representar a relação ou a violência doméstica "homem e mulher", sem trazer a tona outros tipos de relações como a de casais do mesmo sexo ou situações de violências domésticas ligadas às vivências de sexualidades diferentes das referenciadas pela heteronormatividade.

Se tecemos, a partir do que nos toca, do que nos afeta, envolvendo fluxos e agenciamentos vários, um grupo de jovens de diferentes cursos de graduação, que vivem a juventude em uma cidade universitária, não deveria afetar-se, envolver-se, problematizar a multiplicidade? O que os levava a não fazer conexões também com a homossexualidade? Se a diferença não é uma relação entre um e outro, mas simplesmente um devir-outro (LARRAURI, 2009), quando comporiam com ela? 
Figura 2. Simulação de violência entre um casal

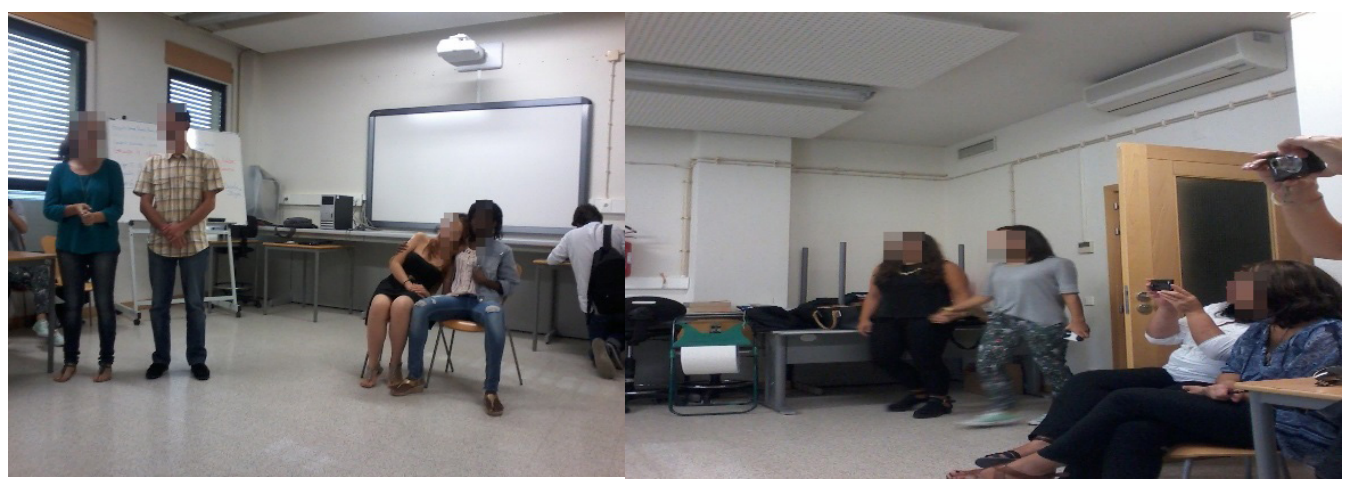

Fonte: Arquivo pessoal das autoras.

À medida que os grupos apresentavam os episódios criados por eles para representar situações de violência doméstica por meio de mímicas, os outros grupos eram convidados a decifrar a mensagem que queriam passar. Neste momento, o 'Outro' instalava-se e atravessava a subjetividade, impedindo uma identidade fechada, convidando ao confronto, a pensar a diferença, a produzir a novidade (DOMÈNECH; TIRADO; GÓMEZ, 2001).

Era no decifrar da mensagem, que a criação de possibilidades que rejeitam a ordem de identificação existente, adquiria imediatamente uma dimensão política. E foi no decifrar a mensagem de um grupo formado por quatro mulheres, em que insinuavam uma briga entre um casal devido à desconfiança desencadeada por uma mensagem de celular que foram convidados / as a produzir outros sentidos para a sexualidade.

Foi quando duas mulheres simularam um casal que uma das professoras do curso disse: "pensei que estivessem representando a relação entre duas mulheres". Possibilidade não pensada pelo grupo até então, mas respondida por uma delas: "é, realmente, não pensamos nisso, mas poderia ser também".

É interessante que o devir homoafetivo só entrou no fluxo do curso a partir da fala/ convite/provocação de uma professora da equipe coordenadora. O fato de nenhum grupo apresentar em suas discursividades, ou representações, situações ligadas à homossexualidade e outros tipos de violência doméstica, ligados à relação entre pessoas do mesmo sexo nos intrigou. Essas questões não atravessariam os/as jovens daquele grupo?

Dentre tantas inquietações algumas perguntas se faziam emergentes sobre os silenciamentos naquelas dinâmicas e os silenciamentos nos cotidianos escolares. O que tem a ver tudo isso com formação de professores/as? O silêncio sentido no grupo em relação às relações LGBTTIs foi para nós um acontecimento, ou uma sequência deles, se assemelhando ao silêncio dos currículos, ao silêncio nas salas de professores/as, ao silêncio nos grupos de trabalho entre docentes em relação à diversidade sexual. Ele poderia ser parte do enraizamento da sexualidade formatada pelo modelo heteronormativo como verdade absoluta, não fosse pela sua ressignificação ao longo do próprio processo formativo.

O projeto de formação para voluntários/as de intervenção no Projeto Nacional de Educaçao pelos pares da Fundação Portuguesa 'A Comunidade Contra a SIDA' (FPCCSIDA) põe em fluxo as temáticas relacionadas à sexualidade e à infecção pelo HIV/AIDS. O falar de 
afeto, de ternura contribui para a maturidade emocional dos/as jovens e a capacidade de lidar com frustrações. Enquanto isso, ao colocar em movimento outras possibilidades de vivenciar a sexualidade, de lidar com o corpo e posteriormente, levar esse debate para as escolas do terceiro ciclo, outros fluxos vão se formando e os silêncios vão se rompendo. São narrativas que se introduzem nas intervenções realizadas para produzir sentidos vários nas formações. Não há como saber o que vai acontecer em cada encontro. Não dá para saber que afetos serão acionados e que redes serão tecidas. Mas uma pluralidade de possibilidades se abriu para aqueles enquanto alguma coisa se move.

\section{Habitar outro campo... Este é o desafio!}

A participação junto à Formação para Voluntários/as de Intervenção no Projeto Nacional de Educação pelos Pares da FPCCSIDA nos fez perceber como a educação sexual contribui para envolver a escola e fazer dela um espaço de autoprodutividade/autocriação. Conforme Silva e Santos (2014), a sexualidade se manifesta na escola, como em outros espaços da vida cotidiana, e é preciso que a mesma seja pensada pelos profissionais da educação. Sobretudo, não é possível que professores/as trabalhem a educação sexual se fizerem da sua docência um ato irreflexo, ou, da sexualidade um exercício de ruborização, de medo ou de moralização.

Essa observação nos parece relevante para pensar as práticas formativas de docentes no Brasil. As experiências vivenciadas em Portugal nos faz refletir sobre a ausência de abordagens relacionadas à sexualidade nas nossas escolas brasileiras e nas práticas formativas. Ainda que tenhamos estudado anteriormente (HERNECK, 2002) os enfoques de cursos de formação continuada de professores/as, somente em contato com esse projeto tivemos a oportunidade de pensar a ausência de tais temas em nossas formações. A experiência de Portugal deixa, assim, possibilidades de outras formações (DELEUZE, 2010) para o contexto brasileiro.

Teixeira (2010, p. 315) afirma que “[...] a educação em sexualidade em contexto formal é, numa perspectiva de direitos humanos, uma urgência educativa [...]”. Os/as professores/as são diversos/as nas suas relações com o seu próprio corpo e nem sempre expandem, em suas problematizações, essas relações aos corpos alheios. As salas de aula podem ser controladas como locais não habitáveis, ou espaços (CERTEAU, 2011) em que a vida possa emergir em suas diversas manifestações. Por isso, o individualismo no tratamento do assunto pode incorrer no risco de instituir práticas controladoras e cerceadoras de acontecimentos, interferindo nos diversos processos de subjetivação por meio de regras, de valores, de limites religiosos e pessoais.

Verificamos que no Brasil conteúdos específicos de Língua Portuguesa e de Matemática são sistematicamente abordados em espaços de formação continuada, todavia, acreditamos que conteúdos voltados à existência e possibilidades de vida da população LGBTTI também devem ser pautados. (HERNECK, 2002). Os discursos adotados por docentes a partir dessas formações podem ser plurais e permitir que mais estudantes sintam-se representados/as nos regimes validados pela prática escolar.

A formação proposta e acompanhada nos mostrou como um trabalho não prescritivo pode ainda ser relevante para o levantamento de problematizações e questionamentos que valorizem os diversos devires. A não prescrição não se limita a uma ausência de objetivos e/ou conteúdo, mas se estabelece nas possibilidades de infinitos agenciamentos, permitindo a diversidade. 
Sexualidade e educação: o Centro de Aconselhamento e Orientação ...

Até mesmo os silêncios gritavam e nos falaram tão alto que criaram inquietações antes também silenciadas em nós. E quando o não dito foi elaborado em um simples comentário, uma pluralidade de possibilidades se abriu para aqueles que se deixaram afetar. Entendemos que processos formativos assim configurados podem ser potencializadores de novas abordagens à temática da diversidade sexual e das vivências sexuais nos mais diversos espaços educacionais. Os diversos acontecimentos que ali se passam configuram-se como disparadores para devires possíveis (DELEUZE, 2010).

\section{Agradecimentos}

À Coordenação de Aperfeiçoamento de Pessoal de Nível Superior (Capes), Programa Nacional de Pós-Doutorado (PNPD), junto à Universidade Federal do Espírito Santo (UFES), pela bolsa concedida para a realização do Pós-Doutorado.

\section{Referências}

ALVES, N. Sobre movimentos das pesquisas nos/dos/com os cotidianos. In: OLIVEIRA, I. B.; ALVES, N. (Org.). Pesquisa nos/dos/com os cotidianos das escolas: sobre redes de saberes. Petrópolis: De Petrus et Alii, 2008. p. 39-48.

AMORIM, A. C. R. Photo grafias, escritascotidiano e currículos deformação. In: FERRAÇO, C. E. Cotidiano escolar, formação de professor(as) e currículo. 2. ed. São Paulo: Cortez, 2008. p. 112-127.

CARVALHO, J. M. Potência das redes de conversações na formação continuada com os professores. In: SÜSSEKIND, M. L.; GARCIA, A. (Org.). Universidade-escola: diálogo e formação de professores. Petrópolis: De Petrus et Alii; Rio de Janeiro: Faperj, 2011.

CERTEAU, M. A invenção do cotidiano: artes de fazer. Petrópolis: Vozes, 2011.

DELEUZE, G. Conversações. São Paulo: Editora 34, 2010.

DOMÈNECH, M.; TIRADO, F.; GÓMEZ, L. A dobra: psicologia e subjetivação. In:

SILVA, T. T. Nunca fomos humanos: nos rastros do sujeito. Belo Horizonte: Autêntica, 2001. p.113-136.

FERRAÇO, C. E. Currículo, formação continuada de professores e cotidiano escolar: fragmentos de complexidade das redes vividas. In: . Cotidiano escolar, formação de professor(as) e currículo. 2. ed. São Paulo: Cortez, 2008. p. 15-42.

. Pesquisa com o cotidiano. Educação \& Sociedade, Campinas, v. 28, n. 98, p. 73-95, 2007. Disponível em: <http://dx.doi.org/10.1590/S0101-73302007000100005>. Acesso em: 7 dez. 2016.

FOUCAULT, M. História da sexualidade: o uso dos prazeres. 7. ed. Rio de Janeiro: Graal, 1994. 
Herneck, H. R.; Ferraço, C. E.; Teixeira, M. F. R.

FOUCAULT, M. Ditos e escritos IV: estratégia, poder-saber. Rio de Janeiro: Forense Universitária, 2003.

HERNECK, H. R. Analisando contribuições de uma política educacional de formação continuada para a aprendizagem da docência: o caso do PROCAP. 2002. Dissertação (Mestrado em Educação) - Centro de Educação e Ciências Humanas, Universidade Federal de São Carlos, São Carlos, 2002.

Formação continuada de professores: níveis de compreensão de uma política pública. 2008. Tese (Doutorado em Educação) - Centro de Educação e Ciências Humanas. São Carlos: Universidade Federal de São Carlos, São Carlos, 2008.

LARRAURI, M. O desejo segundo Gilles Deleuze. São Paulo: Ciranda Cultural, 2009.

LARROSA, J. Pedagogia profana: danças, piruetas e mascaradas. 4. ed. Belo Horizonte: Autêntica, 2006.

Tremores: escritos sobre experiência. Belo Horizonte: Autêntica, 2014.

PORTUGAL. Ministério da Saúde e da Educação. Portaria no 196-A/2010 de 9 de abril.

Diário da República, Lisboa, n. 69, p. 1170-(2)-1170-(4), 9 abr. 2010. $1^{\text {a }}$ série. Disponível em: <https://juventude.gov.pt/Legislacao/Documents/Portaria\%20n. ${ }^{\text {o\% }}$ 20196-A_2010. pdf>. Acesso em: 20 out. 2014.

SILVA, L. M. M.; SANTOS, S. P. Sexualidade e formação docente: representações de futuros professores/as de ciências e biologia. In: ENCONTRO NACIONAL DE PESQUISA EM EDUCAÇÃO EM CIÊNCIAS, 8., 2011, Campinas. Atas... Disponível em: < http://www. nutes.ufrj.br/abrapec/viiienpec/resumos/R0835-1.pdf>. Acesso em: 20 out. 2014.

TEIXEIRA, F. Educação em sexualidade e formação de professores(as). In: TEIXEIRA, F. et al. (Org.). Sexualidade e educação sexual: políticas educativas, investigação e práticas. Braga: Universidade do Minho, 2010. Disponível em: <http://www.fpccsida.org.pt/images/ stories/Livro_I_CISES.pdf >. Acesso em: 7 dez. 2016.

VEIGA-NETO, A. Memória, tempos, cotidianos. In: CONGRESSO INTERNACIONAL COTIDIANO: DIÁLOGOS SOBRE DIÁLOGOS, 1., 2005, Niteroi. Disponível em: <https://twiki.ufba.br/twiki/pub/Pretto/Novas'TecnologiasNaSalaDeAula/Memrias... Rioago2005.pdf >. Acesso em: 20 out. 2014.

Artigo recebido em 05/02/2016. Aceito em 18/08/2016.

Endereço para contato: Universidade Federal de Viçosa, Educação, Av. P. Holffes, s/n, CEP 36570-000, Viçosa, MG, Brasil. 